\title{
Del imaginario urbano a una aproximación de ciudadanía educada ${ }^{1}$.
}

\author{
The urban imaginary to approximate educated citizenry.
}

\author{
Pedro Felipe Díaz Arenas ${ }^{2}$
}

Díaz A.Pedro F. miradas Nº13 - 2015. ISSN: 0122 994X Págs 185 -190

Recepción: Mayo 12 de 2015

Aprobación: Octubre 9 de 2015

Publicación: Diciembre 17 de 2015

\section{Resumen}

El presente texto es una mirada previa al estudio de los imaginarios urbanos, busca identificar el imaginario y el concepto de ciudadanía como fenómeno de ciudadanos educados. Las experiencias de cotidianidad van creando rutas y rutinas, que al ser indagadas remiten a un modo de ser ciudadano.

En este sentido la ciudad es el lugar donde converge y se producen nuevas formas de percibir y de vivir. Este avance está enmarcado en las teorías y metodologías del doctor Armando Silva en el marco del proyecto internacional de ciudades imaginadas en el año de 1994.

Palabras Clave: Comunicación, lenguaje, ciudadanía, estética, educación.

\begin{abstract}
This paper is a preliminary look at the study of urban imaginary, seeks to identify the imaginary and the concept of citizenship as a phenomenon of educated citizens. The experiences of daily are creating routes and routines, that when being investigated refer us to a way of being a citizen. In this sense the city is where it converges and new ways of perceiving and living occur. This development is framed in theories and methodologies of Dr. Armando Silva as part of the international project of imagined cities.
\end{abstract}

\footnotetext{
1 Este documento corresponde a una disertación de tesis expuesta en el panel relación comunicación y educación en el marco del III Coloquio Internacional y IV Nacional: Pensamiento Educativo y Comunicación Educaciones Transmedia y Pantallas a realizarse en la Universidad Tecnológica de Pereira.

2 Docente investigador y director académico de Comunicación social - Periodismo Universidad del Quindío. Magíster en Comunicación Educativa. Candidato a Dr. En Ciencias de la Educación. Líder del grupo de investigación Comunicación: cultura y periodismo clasificado en Colciencias en categoría C. Integrante del grupo de investigación del proyecto internacional ciudades imaginadas, dirigido por el Dr. Armando Silva Universidad del Externado. pedrofelipediaz@gmail. com
} 
Key Words: Communication, language, citizenship, aesthetic, education.

\section{Introducción}

"El espacio público es el lugar de conquista donde convivimos con los demás, pero también donde nos mostramos públicamente. Traspasa lo material para ampliarse a otros territorios simbólicos".

Armando Silva

En el presente artículo se reflexionará las implicaciones de la palabra y sus repercusiones en los modos de habitar lo cotidiano en la urbe actual; lo cual permite nuevas exploraciones del lenguaje visual y referencial en la forma de habitar la ciudad.

Así se posibilita reconocimiento en la forma del cómo se reconfigura nuevos escenarios educativos transversales para los ciudadanos desde el punto de vista del imaginario urbano.

La imagen cobra un sentido de significación en lo cognitivo como experiencia social. Esto ha determinado un nuevo trazado educativo; en las hacinadas urbes, y con ello se acuña una significación permanente de los acontecimientos, y de los modos de habitar lo cotidiano.

En este sentido siguiendo a Silva: "En el interior de las ciudades coexisten distintos territorios, abrumados hoy por el entrecruce planetario de la comunicación de los mass media" (Silva, 2006: 79).

$\mathrm{Si}$ nos dejamos seducir por la figura (imagen) que proyectan los medios; la palabra, del que deriva, impulsa a la apertura de horizontes educativos, predeterminados por la información, la cual no se cierra en estructuras fijas, no se centra en la exclusividad, sino que permite una metamorfosis virtual del contexto al cual se refiere un imaginario.

Ello implica el des-apropiarse de lo establecido en la estructura educativa, y se constituye como nómada; un desplazamiento de un imaginario producido por la educación tacita de lo mediático.

Fernando Carrión al referirse al concepto de frontera plantea cinco problemas, y me referiré al problema numero dos que aplica para el contexto colombiano: "los medios de comunicación invisibilizan o estigmatizan la realidad de la frontera produciendo una agenda pública distorsionada" (Carrión, 2011: 80)

Atender a estas transformaciones mediáticas a nómada por la presencia del imaginario social frente a un determinado espacio urbano, implica también la reconfiguración de la educación, de irrumpir la vida cotidiana del ciudadano.

Es así como emerge una metáfora de ciudad interpuesta por los medios de comunicación. En definitiva afirmar que el acercamiento escritural, tendrá como pretensión el recorrido por la imagen que transita y muta en el imaginado por los habitantes de un contexto.

\section{Reflexión}

\section{Un imaginario educativo - mediático}

Los acercamientos con la palabra, han sido encaminados desde lo pedagógico instrumental, siendo moderados y silenciados por la imagen, producidos por lo mediático como consecuencia en el desarrollo de la vida urbana.

Esto determina una serie de esquemas establecidos. En ocasiones las políticas públicas de urbanismo toman distancia con el imaginario urbano social, lo que es, lo factible y no factible, en lo determinado por las pronunciaciones que sobre educación se realiza y que delimita la relación educación - medios de comunicación - imagen.

Jordi Borja afirma: "El proceso hacia la ciudadanía requerirá un doble proceso político-jurídico:por un lado, la legalización 
del habitante (papeles, ocupación) y, por otro legalización del territorio": (Borja, 2003:110).

Pero limitación no se queda allí, también es irrumpida por las categorías morales de lo que se puede y no se puede informar en lo mediático con relación a la escuela.

También se denominará a aquellos que escriban sobre su realidad, su contexto y su vitalidad; pero este fenómeno es mucho más agudo en los cuestionamientos y las posturas críticas frente a lo estipulado por los medios masivos de comunicación; se denominará que la información y el uso del discurso no son coherentes con respecto a la vida cotidiana, a demás de quien lo realice como un juego de palabras e imágenes generara un imaginario social mediático.

Se produce un tipo de esquizofrenia urbana y de seguridad pública que reconoce un interés en la inmovilidad de la palabra que la lleva al enclaustramiento de la imagen como única verdad, esto transformado en dato estadístico, es decir, aquellas palabras que han permanecido en los modos de ser, han explorado una mutación a lo numérico como una interpretación del imaginario social y de estadística educativa.

\section{La configuración como realidad de acción}

Hay que comprender que imaginario va más allá de los escenarios estáticos y deterministas, además genera transformaciones; así se puede señalar que la imagen es acción, si, es acción; es movimiento y si es lo anterior es cambio, mutación, esto alude a un sentido de la relación ciudadano - imaginarios educación respecto a un desplazamiento del concepto de percepción social.

Hablar entonces de imaginario, en este sentido y en un contexto; es reflexionar más allá de lo informativo, es decir, la palabra e imagen en la información puede ser contraproducente en la medida que remite a una acción sobre un territorio en un contexto educativo como sujetos sociales.

La información permite comunicar horizontalmente, y dista del encuentro de experiencias sociales y educativas, que aportan una reconfiguración de nuevas sensibilidades orientadas desde la educación, debería apropiar sentidos de posibles realidades de un imaginario ciudadano urbano.

Esta acción moviliza el cambio como escenario dialógico desde la interacción en el encuentro con el otro, y con la necesidad de tejer territorialidades vitales de los ciudadanos. Para resignificar la palabra Zygmunt Bauman plantea con este ejemplo la noción de territorio: "El macho del pez espinoso construye un nido para que la hembra desove y almacene sus huevas, y protege el nido hasta que las crías emergen de la huevas.

Una línea divisoria imaginaria separa el "territorio propio" alrededor del nido (es decir, el espacio que el macho defiende contra los intrusos, atacando a todo espinoso macho que ose penetrar el perímetro) del territorio ajeno" (Bauman, 2004:95)

Esta lectura de como la información impone subjetividades-colectivas, lo mediático anuncia desde un confort periodístico sin pretensión de colocar en evidencia los lugares que están entendidos como territorio- educación, existe un serie de recepción de aquellos lugares y zonas que tiene un estigma aparente a través del tiempo, o mejor han generado todo un ritual social y cultural como expresión imaginaria.

Esto se construye entonces en una cultura de la prolongación en su existencia por medio de una narrativa propia; dando reconocimiento a la subjetividad y la tecnología como apropiación que permite una construcción del discurso desde los usos 
autónomos como una acción comunicativa o de información de esa palabra como polisemia.

Es decir; cuando se realiza la acción se está modificando al mismo tiempo múltiples significados según el receptor y el contexto, se está en un permanente devenir, donde se construye permanentemente realidad de un territorio educativo.

La imagen relaciona y altera un principio de percepción

La acción metafórica, el hacer simbólico, la transfiguración y reconfiguración de la realidad se da también desde la actividad misma del ciudadano, ya que la imagen y la palabra aparece como acción.

Entonces, podríamos atrevernos a señalar que las acciones performativas y estéticas que emergen en actuales territorialidades cotidianas, son producto de la reflexión que realiza el ciudadano para comprender un medio estructurado por condiciones textuales bajo la esfera de la percepción.

La aparición de lo imaginarioy lo simbólico, es producto de aquellas manifestaciones sensoriales y afectivas que los individuos configuran sobre su realidad para provocar en ella aproximaciones, para denunciar lo que no se admite, para transgredir y subvertir esas normatividades que limitan el entorno urbano.

Las manifestaciones mediáticas que generan imagen y atraviesan caminos fuera de lo estipulado, hacen su presencia en espacios cotidianos, que aunque son determinados y organizados por estructuras económicas, educativas y de política pública o del sector privado, no dejan de ser los escenarios perfectos para romper los dispositivos de poder y de control, que en últimas, lo único que hacen son coartar encuentros confusos, metafóricos y oníricos.
Siguiendo a Joly: "las palabras están, en los periódicos, en los libros, que nos demuestran hasta qué punto las imágenes pueden alimentar la imaginación" (Joly, 2003:83) Es desdibujar la realidad para provocar en ella otras posibilidades de decir realidad.

Esos lugares y espacios en los cuales se hacen posible dichas acciones de ruptura, se encuentran en ese territorio geográfico que posee movilidades y lentitudes de distintos tipos, es un devenir cromático como lo puede ver el ciudadano.

Aquel territorio es la ciudad comprendida como escenario sobre el cual se hacen presente manifestaciones urbanas, ciudades donde los flujos de comunicación permiten ese uso como referencia para entender unas posibles complejidades con sentido transversal de la palabra, en el rol de ciudadano como habitante de la ciudad y uso del lenguaje como artefacto provocador educativo.

A través del territorio se hacen presentes todas las posibles lecturas de los símbolos que, de una u otra forma, son las que hacen evidentes las percepciones y visiones de lo urbano; dichos símbolos configuran el mundo imaginario para comunicar, evidenciar y permear la percepción social de determinado fenómeno.

Cuando nos referimos a lo que es la ciudad, se realizan cuestionamientos que inciten a su reconocimiento y a su encuentro, desde la posible palabra como una acción con relación al (otro) es comunicar.

Siguiendo a Amendola "la ciudad nueva contemporánea deriva directamente de la ciudad-espectáculo barroca enseñando, sin embargo, una importante mutación genética" (Amendola, 2000:158) se comprende que es en la ciudad donde el sujeto hace la aparición de sus deseos, 
de sus angustias, de sus proyecciones, de su forma propia de comunicación, construida cotidianamente en metáforas y complejidades.

También se debe admitir que es el ciudadano quien crea su territorialidad y su ciudad, promoviendo escenarios educativos de reflexión y confrontación por medio expresiones estéticamente desdibujadas en momentos por imágenes que hacen de la ciudad un reflejo de múltiples interpretaciones y concepciones urbanas.

Esa configuración de visiones de realidad, lleva a cuestionar sobre el papel que cumple el concepto de lo cultural en las territorialidades, marcada por los medios de comunicación y la educación, en este caso, un ciudadano educado para ser urbano, cómo se hace parte de esas reconfiguraciones de nociones de lugar y de espacio para resignificar los posibles modos de percepción educativa.

\section{Lo mediático como proyecto semiológico}

Acogiendo la ruta planteada por Silva: "Entonces la comunicación objetiva debe atender al proceso descodificador de los signos - aparentes- en que se nos presentan los lenguajes para que mediante sus desenmascaramientos podamos entrar a la estructura profunda donde esta el verdadero significado del fenómeno (Silva, 1978:77).

Se diría que los estudios del lenguaje encausarían su atención luego de un primer momento lingüístico hacia las distintas prácticas sociales en concordancia operacional con la lengua, serian susceptibles de ser estudiadas.

La comunicación configura y centra un proceso de códigos que condicionan cierto territorio desde la noción de alerta en la movilidad de los ciudadanos. La dinámica del lenguaje en la semiótica considera que la comunicación debe generar producción e intercambio de sentido.

Para Ford: "Es difícil hablar de los medios, de sus géneros, de sus formas de construcción de sentido, de su producción o recepción" (Ford, 2001: 127), quizá refiere a la forma como se elaboran los contenidos para su interacción social y adaptación cultural del fenómeno urbano.

Lo anterior puede verse a través del escenario donde se desarrollan las prácticas sociales, en palabras de Enrique Finol: "El espacio es una estructura semiótica que cumple un papel fundamental en la organización de la cultura... se convierte en instrumento simbólico, capaz de articular los contenidos de la cultura misma en una sintaxis particular" (Finol, 2006:95).

Para la escuela semiótica los lugares y objetos de la vida diaria son, por su propia naturaleza, ordinarios y sus significados sociales no son siempre evidentes, aquello que se considera como sentido o vida común - experiencia que se expone en relación con el otro, consigo mismo y con su entorno.

La configuración de lo educativo como escenario en el que se concretizan prácticas, develan huellas que un determinado lugar puede llegar a establecer en torno a las relaciones que dicho ambiente, despierta en quienes lo vivencian y que logran extenderse en sus fronteras espaciales.

La ciudad, en tanto texto, es un ejemplo claro de la lectura que se referencia, toda vez que como cual palimpsesto que además de ofrecer la posibilidad de ser leída, despierta el ánimo para ser escrita, expresada y relatada a través del sentir de quienes la viven y la recorren; es allí el modo concreto del operar analógico 
que estableció el movimiento del estudio del lenguaje alrededor de la lengua y las prácticas sociales.

La incorporación de la semiótica a los estudios comunicacionales permitiría, a partir de la década de los setenta, una integración a las dinámicas sociales y nuevos modos de abordar diferentes esferas de la vida.

La hegemonía del libro y del lenguaje escrito que imperaba en un primer momento para el estatuto comunicacional, se verá movilizada en esta etapa donde ocurre un descentramiento del lenguaje, lo que conllevará nuevas formas de lectura, como el de la imagen.

Las implicaciones que desde el campo social sitúan las consideraciones de las perspectivas que de éste se desprendían a partir del enfoque científico que se pretendió constituir en las prácticas sociales, que se ubican en la función estética desplegada en la teatralidad humana, Silva nos presenta la síntesis del trayecto al plantear que:

"En las ciudades colombianas el miedo se extiende. Los ciudadanos ven y sienten peligro por todas partes. A los miedos tradicionales se agregan nuevos: el temor al atraco, el miedo a la bala perdida proveniente de luchas entre grupos contrarios, algunos sectores temen al secuestro mientras otros padecen la amenaza de ser desalojados, las mujeres agregan el miedo a la violación, y los niños el ser raptados. El miedo se extiende a otras esferas distintas de la desprotección física" (Silva, 2008:87)

A parte del salto de lo técnico a lo estético, podría concluirse igualmente que el lenguaje transita nuevas configuraciones imaginarias, en las cuales, de manera singular, la dupla tecno - estética, adquiere grandes connotaciones en el territorio educativo marcado por imaginarios sociales.

\section{Referencia Bibliográfica}

Amendola, G. (1997). La ciudad Postmoderna. Roma: Celeste ediciones.

Bauman, Z. (2004). La sociedad sitiada. Argentina: Fondo de cultura Económica.

Borja, J. y Zaida M. (2003). El espacio público: ciudad y ciudadanía. Barcelona: Electa.

Carrión, F. y Espín, J. (2011). Relaciones fronterizas: encuentros y conflictos. Ecuador: Flacso Ecuador.

Ford, A. (2001). Navegaciones Comunicación cultura y crisis. Argentina: Amorrortu editores.

Joly, M. (2002). La interpretación de la imagen. Barcelona: Paidos.

Silva, A. (1978). La comunicación visual. Colombia: Ediciones Suramérica.

Silva, A. (2006). Imaginarios urbanos. Colombia: Arango editores.

Silva, A. (2008). Los imaginarios nos habitan. Quito: OLACCHI.

Silva, A. (2013). Imaginarios, el asombro social. Colombia: Editorial Universidad Externado de Colombia. 